\title{
Editorial
}

\section{Teaching in the Age of Digital Reason}

From Teaching as a Moral Pursuit to Teaching as a Technological Practice

\author{
Michael A. Peters \\ Faculty of Education, Beijing Normal University, China PR \\ mpeters@bnu.edu.cn
}

\author{
Xudong Zhu \\ Faculty of Education, Beijing Normal University, \\ China PR \\ zhuxd@bnu.edu.cn
}

\begin{abstract}
Teaching, born of the period of the ancient sages, developed as the moral art of living that introduced humanity to teaching as a moral pursuit, to the formation of value, to a moral and religious mode of being, and to a set of moral principles that have survived into the modern day. The idea that the 'future of teaching' represents a technological disruption of moral traditions of teaching and what teaching might become has become a serious concern for the current generation of philosophers in both China and the West. This editorial examines these issues and introduces this special issue.
\end{abstract}

\section{Keywords}

future of teaching - ancient sages - moral traditions - technological disruption Moocs 
The ancient sages created 'teaching' as the moral transmission of virtue in the tradition of wisdom that took place in both Eastern and Western traditions. The teachings of wise men became a form of philosophy that utilised proverbs, questions, examples, riddles, paradoxes, enigmas, fables, parables, dialogues and other literary expressions to grapple with practical problems in life, to provide meaning, and to arrive at a lifeworld in a practical sense that determined the principles of conduct, governed society and informed the social good. The teachings of the ancient sages were the basis of wisdom that historically created 'teaching' and philosophy as a way of life, a contemplative attitude toward existence and a comprehension of the nature of humanity and its place in the cosmos. The ancient sages existed in Persia, Egypt, China, India, Greece, Syria, Japan, Korea to mention some of the main traditions that founded Hindu, Chinese, Hebrew, Greek and Christian cultures. Records of their undertakings and teachings go back over five thousand years. Not only are they associated with spiritual teachings and ancient texts (and with writing and reading) but also with healing. The sages were centrally concerned with relieving people's sufferings. They often tried to integrate virtuous living and morality with systems of governance in order to achieve peace between warring parties to produce a social integration and harmony. The first sages were products of early nomadic life, in which books were unknown and the practical wisdom gained by experience was treasured in the minds of certain men who were called the wise or sages. To them knowledge was not an end in itself by rather related to practical problems in life that the people experienced.

Students, followers and disciples of the ancient sages had to learn to master their passions through a series of spiritual exercises that elaborated a metaphysical worldview that was exemplified by the figure of the sage as a living embodiment of wisdom that symbolised the excellence and virtue of the soul and a constant inner state of happiness, peacefulness or serenity. Most sages valued study and committed themselves to years of scholarship and learning before they took on students. They provided the ultimate justification of learning and education based on the idea that one should actively pursue learning and studying to become nobler and more virtuous.

Teaching in its classical sense was inseparable from the ancient sages who invented it as part of the wisdom tradition and established schools that were concerned with the preservation of teachings and their transmission. These teachings took many different forms leading to genres that best communicated scriptures and scared texts. From the beginning teaching was developed as the moral art of living. The problems, themes, methods from which teaching 
has developed were born in the period of the ancient sages and succeeding generations have paid homage to and provided criticism of these ways of living, the expressed virtues and modes of behaviour. These ancient beginnings have introduced humanity to teaching as a moral pursuit, to the formation of value, to a moral and religious mode of being, to a set of moral principles that have survive through the generations and period of history into the modern day. The moral teaching of the ancient sages also bequeathed to us theories of pedagogy, instruction, and learning as the basis for the good life that survives in both its religious and secular forms as teaching the good citizen. The sage a teacher, master, guide, expert - through mysticism, textual exegesis, rational thought, meditation and spiritual exercises, shares accumulated knowledge, moulds character, provides guidance as a life exemplar, and provides inspiration to students schooled in the tradition of a body of precepts and texts. In Jainism, Buddhism, Confucianism, Hinduism, Sikhism, Socraticism and Christian thought the teacher had a revered, sometimes holy status, of someone who had acquired special knowledge and could reveal truths about this world. We find that most indigenous cultures also created such a tribal role. It is clear that this is a multifarious and diverse set of origins of teaching that despite their variety share many features that survive into today's global society. Some critics even argue that education suffers a moral and spiritual crisis (e.g., Purpel et al. 2004) and much work in education and teaching is seen as reconnecting with indigenous cultures and historical origins to gain a better understanding of ourselves and our spiritual condition or the consequences of its lack. How do we reconnect with our moral traditions, to enhance and develop our moral intuitions, preserving the teachings of the sages in a digital environment? Digital technologies provide greater access to cultural archives in publicly available online systems that preserve but decentre the sage and the teacher in the logic of distributive systems which disrupt the relationship of teacher-student to emphasise 'flat hierarchies' and greater peer learning with an emphasis of horizontal relationships.

The idea that the 'future of teaching' represents a technological disruption of moral traditions of teaching and what teaching might become is a serious concern. Will the technological future of teaching disrupt, diminish and break down teaching as a moral tradition? In this concern we also raise a concern for competing notions of 'future' as a form of historical time that drives the history of comparison. As far as the first question arises to what extent will 
the future resemble past cultural models? Will digital technologies of teaching weaken past cultural models of teaching if they are allowed to replace or augment the teacher? Technology on its own, like science, has difficulty setting its own values when everything is based on the efficiency, effectiveness and speed of communication. Digital technologies in the service of an historical 'return' to great moral traditions of self-cultivation and to traditions of critical theory may be considered a form of 'technological augmentation' of teaching that can preserve: the teacher in the wisdom tradition; the teacher in the Enlightenment tradition as an agent of social transformation; and the teacher in the Marxist tradition as an agent of revolutionary change and social justice.

The future of teaching as the technological disruption of moral traditions we call 'teaching in the age of digital reason', an account that emphasises digital transformation and automatic development of education, with machine teaching and instruction, the digital augmentation of teaching as evidenced in MOocs, and the technologies of evaluation. It is based on an assessment of cybernetic rationality in its fourth or fifth generation, including the notion of calculation of a two-value logic. The discourse of the future of teaching is a thesis about technical transformation of the future as if technology is a neutral, autonomous and determining force where the future of teaching becomes a teleology driven by the technological imperative, a form of technological disruption of past cultural, moral and political models of teaching. In short, this view is teaching as a technological practice or invention with an emphasis on machine teaching and learning, automatic teaching, with an overriding emphasis on the question of cognitive efficiency. The digital represents a new episteme and a new condition for the nature and possibility of knowledge. It transforms reading and writing to function as a general technological horizon of education and teaching, functioning in the same way as writing once did in antiquity.

Yet the technological transformation of teaching is a hyper discourse given to high-sounding rhetoric. Take the example of Massive Open Online Courses (MOOCs) that emerged in the early years of this decade. The New York Times dubbed 2012 the year of the moocs. Quite suddenly, the discourse of moocs and the future of the university hit the headlines with influential reports using the language of 'the revolution to come' (e.g. Barber et al. 2012; Ernst \& Young, 2011). Most of these reports hailed technological change and predicted a transformation of the traditional university delivery of teaching and higher education through competition from private venture for-profit and not-for-profit partnerships.

The development of Moocs globally should be seen within the theoretical framework of post-industrial education, distance education and venture capitalism. This is especially evident in the USA where social media has become a 
dominant cultural phenomenon and where new era business models focus on for-profit institutions, for-profit online courses, learning management systems, where there is an increasing alignment of consortia of universities, big media and multinational publishing companies setting up new commercial synergies between Moocs, e-books and video content. While moocs are an extension of existing forms of distance education as an online learning approach with its home in the movement of open education, both increased scalability and new business models offer opportunities for innovation.

'Learning analytics' is another term used by those in the education community who are seeking to understand the implications of these developments for how we use learning data to improve learning systems. Learning analytics involves the use of computational techniques to analyze learner data, generate visualizations of learning dynamics, and build predictive models to test theories. Data can be gathered in real time and there is a possibility of continuous improvement via multiple feedback loops. There are many issues not least to do with control, access to data, authority to access data and student surveillance. Big data represents a fundamental transformation of science from hypothesis-testing models to data-driven discovery where AI programs can organise and detect deep configurations in data intensive streams and feed them back to programmers.

This new digital environment that represents the confluence of two major forces of information and new biology we can talk of the bio-informational society that has the capacity to speed up and change human evolution (Peters, 2012). The analysis of cybernetic rationality and the forms it takes within the large algorithmic systems of the global info-utilities, its replacement of the old gas and oil industries of industrial capitalism, and its dominance of education in the so-called knowledge economy, is required. Search engines have largely replaced libraries and digital archives of book, journals and teaching materials are available, often free, on the internet. There are important possibilities within the current digital paradigm for the promotion of 'public knowledge cultures' that involve the development of new journals, open publishing, the intellectual commons that signal the virtues of openness, collaboration and connectedness (Peters and Roberts, 2012).

Open education has involved a commitment to openness in the broadest terms and is seen by advocates as a political and social project. The concept of openness in regard to education predates the openness movement that begins with free software and open source in the mid-1980s with roots going back to the Enlightenment that are bound up with the philosophical foundations of modern education with its commitments to freedom, citizenship, knowledge for all, social progress and individual transformation. These early origins and 
the basis for open education have been expressed in a variety of forms from the 'open classroom' to the 'open university'. Political, social and technological developments have taken place in parallel with the history of the movement of open education that have heightened certain political and epistemological features and technologically enabled others. These emphasise questions of access to knowledge, the co-production, co-design and co-evaluation of educational programs and of knowledge, the sharing, use, reuse and modification of resources while enhancing the social ethics of participation and collaboration. Open education as a movement sits within the broader framework of the history of openness that brings together a number of disciplines and fields to impact directly upon the value of knowledge and learning, their geographic distribution and ownership, and their organization.

The movement toward greater openness clearly represents a change of philosophy, ethos, and governance and a set of interrelated and complex changes that transform markets, altering the modes of production and consumption, ushering in a new era based on the values of openness: an ethic of sharing and peer-to-peer collaboration enabled through new architectures of participation. These changes indicate a broader shift from the underlying industrial mode of production, from a productionist metaphysics to a post-industrial mode of consumption as use, reuse, and modification where new logics of social media structure different patterns of cultural consumption and symbolic analysis becomes a habitual and daily creative activity. The economics of openness constructs a new language of 'prosuming' and 'produsage' in order to capture the open participation, collective co-creativity, communal evaluation, and commons-based production of social and public goods.

The social processes and policies that foster openness as an overriding educational value is strongly evidenced in the growth of open source, open access, and open education and their convergences that characterize global knowledge communities. Some observers argue that openness seems also to suggest political transparency and the norms of open inquiry, indeed, even democracy itself as both the basis of the logic of inquiry and the dissemination of its results based on concept of the open society and open government that aims to promote strong citizenship participation. With the advent of the Internet, Web 2.0 technologies and user-generated cultures, new principles of openness have become the basis of innovative institutional forms that decentralize and democratise power relationships, promote access to knowledge and encourage symmetrical, horizontal peer learning relationships. In this context, radical openness is a complex code word that represents a change of philosophy and ethos, a set of interrelated and complex changes that transform markets, the mode of production and consumption, and the underlying logic of our institutions (Peters, 2013a). 
It is not clear at this stage whether or how Moocs or other technological teaching improvement will advance these values. The theory of openness points to fundamental differences between the logic of industrial systems and that of information systems. Computer-based information systems embrace all forms of automation, expert systems, search engines, management information and processing systems that include both hardware (monitor, processor, printer and keyboard) and software (the programs), together with databases and networks that make up what is known as the information technology platform. These can provide truly global systems based on algorithms that have a kind of scalability that dwarfs the old assembly line production. Social media differs from industrial media: social media are based on Internet-based applications that build on the ideological and technological foundations of Web 2.0 and enable user-generated content. In this sense, then, moocs might be seen as a form of industrially scaled automation of the teaching function that uses Internet platforms to deliver content globally. moocs are based on the traditional one-to-many broadcast principle rather than the many-to-many, horizontal peer-learning structures (Peters, 2013b; Peters et al., 2014; Peters, 2016). The major pedagogical question is to what extent massively large online classes permit or encourage peer learning or interaction?

More broadly, we would argue that technology-based teaching systems based on the values of openness represent the best option for the enhancement and preservation of the teaching of the sages. Open systems of teaching provide an opportunity to further develop and enhance the philosophy the 'ideal learning community' (Marshall \& Peters, 1985) and 'communities of inquiry'. It allows for innovation within larger digital infrstructures.

\section{Cultural Models of Historical Thinking}

How do we think history, the future and time? There are differences between Chinese and Western modes of representation of history. Chinese historical thinking is dialectical - it is both historical and transhistorical, subjective as well as objective and to that extent differs from the way historical thinking is employed in the mathematical and natural sciences in the West. Yet there is a dialectical interdependence of opposites that appears in the works of Hegel and Marx but Chinese dialectics historically is more fluid and open-ended, a fact that partially explains the ready acceptance of Marx in China. It offers us the wisdom tradition not the science that Hegel and Marx claimed (Liu, 2006: 93). The ancient Chinese notion of time going back to the Yi Jing, dating from $672 \mathrm{BCE}$, tends to organise time in cyclical terms with each iteration indicating new content rather than a mere repetition of the past. The Western 
view, by contrast, is both absolute and linear at least until the twentieth century that promoted a teleological concept of time that has a cause ordained by the creator-god, and a beginning and end, including the world which in the Judaic-Christian tradition has a distinct beginning and will come to an end one day. This model of time that grows out of its Christian past becomes associated with a progressive idea of history in which time moves forward without repeating itself. Only recently have these Christian assumptions vitiated Western cultural models of time and arranged for the future to be seen in linear and progressive terms both morally and political. Quantum as opposed to classical mechanics leaves us only with a non-deterministic and probabilistic universe based on a 'space-time' continuum. This is to emphasise the unique values of the Chinese traditional notion of cultural time which recognises the subjective, flexible and relative characteristics contrasting with the western world's emphasis on the objective, absolute, and future-focus time orientation (Huang \& Henderson, 2006).

The future of teaching will be determined by digital technologies and the internet but not independently of history, culture and politics. In political terms, the future of teaching itself might be seen in terms of three contemporary political approaches: the professionalization agenda, the deregulation agenda and the social justice agenda that ties the question of teaching firmly to teacher education. Zeichner (2003: 289) argues:

The professionalization agenda has sought to raise the status of teaching as an occupation by advocating policies that have led to the use of the performance assessments based on standards and various kinds of paper and pencil tests of subject matter knowledge, professional knowledge, and basic skills to assess candidates' readiness for certification. These measures in part, are intended to convince a skeptical public and policymakers that there is specialized knowledge beyond a liberal arts education that teachers need to teach well (ibid). (See also Zeichner, 2009.)

There are different interpretations of professionalization as there are of regimes of accountability. Often professionalization expresses itself politically as a call for robust forms of teacher evaluation through national accreditation programs, with ongoing support for the professional development of teachers. By contrast, the deregulation movement has encouraged alternative forms to state teacher education programs with an accent on the privatization of education, teacher education and corporate models of global citizenship education. The social justice driven teacher education model looks to equalisation through active recruitment and retention policies aimed at minority and 
indigenous populations to encourage greater diversity, equity and racial justice. This movement has led to cultural responsive pedagogies and an exploration of models of multicultural and intercultural learning.

We planned this issue many months ago and issued the following Call for Papers:

\section{The Future of Teaching and Teacher Education}

Teaching and teacher education are inherently political. Depending on political perspective teachers may or may not require education and training; the best teachers are masters of content or talented performers; teachers are born not made. Current debates revolve around contentious issues: the best teaching can and should be objectively measured across institutions; teachers should be responsible for student learning; levels of pay and working conditions are critical to teacher excellence; teacher education reduces teacher quality; teacher require both theory and practice; constructivist learning theory is most suited to teacher education; current teacher education is not longer based on the reflective practitioner but rather neoliberal docile state workers. Dirk Van Damme (OECD, 2017:3), Head of the Innovation and Measuring Progress Division, Directorate for Education and Skills at the OECD holds that 'highly qualified and competent teachers are the key for excellent education systems' and that teachers 'are expected to process and evaluate new knowledge relevant to their core professional practice and to regularly update their profession's knowledge base.' Thus, it is argued, we need to know 'What is the nature of the pedagogical knowledge base of the teaching profession?' Some observers argue that teaching is the key to the knowledge economy in the sense that it is the foundation of lifelong learning. It must therefore focus on all the elements of a human service profession in order to recruit the most talented people with the requisite qualifications, aptitude and understanding of learning difficulties. These future teachers must also be attuned to youth culture and to the technological disruption that faces society with the strong consequence of technological unemployment. The clarion call of the twenty-first century for teaching and teachers has been 'quality'; today in face of multiple problems of globalization we might substitute the ideas 'complexity', or 'responsibility' or 'disruption' or 'action learning'. 
We received a large number of papers and responses and, given the richness of the contributions, we decided to publish a double issue. It has the following structure: a section called 'The Future of Teaching in 500 words', a section that consists of normal academic articles, and a final section called 'China Watch'. The first section is a condensed form that offers the possibility of hearing from a range of thinkers in 500 words. There are some longer pieces as well up to 1500 words. 'China Watch' is a section edited by Professor Jun Li that focuses on reforms in China. It will become a constant feature. The issue contains also a number of articles that address the theme on the future of teaching and teacher education by noted world scholars, both Chinese and Western. We are very grateful to our contributors who have contributed to this issue of The Beijing International Review of Education and would also like to thank members of the editorial team whom organised and carried out the peer review process.

\section{References}

Barber, M., Donnelly, K. and Rizvi, S. (2013). An Avalanche is Coming: Higher education and the revolution ahead, http://www.ippr.org/publication/55/10432/ an-avalanche-is-coming-higher-education-and-the-revolution-ahead.

Chun-chieh Huang and John B. Henderson (Eds.), (2006). Notions of time in Chinese historical thinking. Hong Kong, Chinese University Press.

Ernst \& Young's (2012). Universities of the Future, http://www.ey.com/Publication/ vwLUAssets/University_of_the_future/\$FILE/University_of_the_future_2012.pdf.

Liu, Shu-hsien, (2006). On the formation of a philosophy of time and history through the Yijing. In: Chun-chieh Huang and John B. Henderson (Eds.), (2006). Notions of time in Chinese historical thinking. Hong Kong, Chinese University Press.

Marshall, J. and Peters, Michael A. (1985). 'Evaluation and Education: The Ideal Learning Community' Policy Sciences Vol. 18, No. 3 (Nov., 1985), pp. 263-288.

Peters, Michael A. (2012). Bioinformational capitalism, Thesis Eleven, 110(1), 98-111.

Peters, Michael A. (2013a). Massive Open Online Courses and Beyond: The Revolution to Come, TruthOut, https://truthout.org/articles/massive-open-online-courses -and-beyond-the-revolution-to-come/.

Peters, Michael A. (2013b). The Concept of Radical Openness and the New Logic of the Public, Educational Philosophy and Theory, 45:3, 239-242, Dor: 10.1080/ 00131857.2013.774521.

Peters, Michael A. (2016). Inside the global teaching machine: Moocs, academic labour and the future of the university, Learning and Teaching, https://doi.org/10.3167/latiss .2016.090204, pp. 66-88.

Peters, Michael A. and Roberts, Peter (2012). The Virtue of Openness: Education, Science, and Scholarship in the Digital Age. Boulder, Paradigm Publishers. 
Peters, Michael A., Besley, Tina \& Gordon, Liz (2014). The Development of Massive Open Online Courses (Moocs) in New Zealand, https://ako.ac.nz/knowledge-centre/ massive-open-online-courses-moocs/.

Zeichner K. (2003). The adequacies and inadequacies of three current strategies to recruit, prepare, and retain the best teachers for all students, Teachers College Record, 2003;105(3): 490-515.

Zeichner K. (2009). Teacher education and the struggle for social justice. London: Routledge. 